\title{
PEMBELAJARAN SOFT SKILL KOMUNIKASI UNTUK MENINGKATKAN KEMAMPUAN KOMUNIKASI MATEMATIS SISWA
}

\author{
Muhammad Nur Wahyu ${ }^{1}$, Sugeng Sutiarso ${ }^{2}$, Haninda Bharata ${ }^{3}$ \\ ${ }^{, 2,3}$ Prodi Magister Pendidikan Matematika, FKIP, Universitas Lampung, Jl. Prof. Dr. Ir. Sumantri Brojonegoro \\ No.1, Kota Bandar Lampung, Indonesia. \\ nurwahyu45@gmail.com
}

\begin{abstract}
The purpose of this research is to examine the student's mathematical communication skills using learning soft skills of communication with ordinary learning. The study used the research experiment. Research Design using Nonequivalent Control Group Design. The population in this study were all students of class XI of mediumskilled vocational high school, while the sample was chosen by class XI of 50 people from one vocational school in central Lampung with medium ability. The instrument in this study was in the form of a test item in the form of a description for a test of mathematical communication skills. The instruments used have fulfilled good questions based on validity, reliability, distinguishing features and difficulty index. Based on calculations using SPSS 20, the following results are obtained for the achievement and mathematical communication skills of students whose learning using soft communication skills learning is better than ordinary learning.
\end{abstract}

Keywords: Communication Skills, Learning Communication Soft Skills

\begin{abstract}
Abstrak
Tujuan dalam penelitian ini adalah untuk menelaah kemampuan komunikasi matematis siswa menggunakan pembelajaran soft skills komunikasi dengan pembelajaran biasa. Penelitian yang digunakan yakni penelitian Eksperimen. Desain Penelitian menggunakan Nonequivalent Control Group Design. Populasi dalam penelitian ini adalah seluruh siswa kelas XI SMK yang berkemampuan sedang yang berada di lampung tengah, sedangkan sampelnya dipilih kelas XI yang berjumlah 50 orang dari satu SMK di lampung tengah yang berkemampuan sedang. Instrumen pada penelitian ini berupa tes berbentuk soal uraian untuk tes kemampuan komunikasi matematis. Instrumen yang digunakan sudah memenuhi soal yang baik berdasarkan validitas, reliabilitas, daya pembeda dan indeks kesukaran. Berdasarkan perhitungan menggunakan SPSS 20 didapat hasil sebagai berikut pencapaian dan kemampuan komunikasi matematis siswa yang pembelajarannya menggunakan pembelajaran soft skill komunikasi lebih baik dibandingkan pembelajaran biasa.
\end{abstract}

Kata kunci: Kemampuan Komunikasi, Pembelajaran Soft skill Komunkasi

\section{PENDAHULUAN}

Tujuan pendidikan kejuruan tingkat menengah (SMK) adalah mempersiapkan siswa terutama untuk bekerja dalam bidang tertentu sesuai dengan kompetensi keahlian yang dimiliki. Sekolah Menengah Kejuruan (SMK) adalah salah satu lembaga pendidikan yang berusaha menyiapkan tenaga kerja yang siap pakai. Salah satu tujuan SMK adalah menyiapkan siswa agar menjadi manusia produktif, mampu bekerja mandiri, mengisi lowongan pekerjaan yang ada di dunia usaha dan di dunia industri sebagai tenaga kerja tingkat menengah sesuai dengan kompetensi program keahlian yang dipelajarinya.

Proses Pembelajaran pada tiap satuan pendidikan diselenggarakan secara interaktif, inspiratif, menyenangkan, menantang, memotivasi siswa untuk berpartisipasi aktif, serta memberikan ruang yang cukup bagi prakarsa, kreativitas, dan kemandirian sesuai dengan bakat, minat, dan perkembangan fisik serta psikologis peserta didik. Pembelajaran yang efektif adalah Pembelajaran yang bukan saja terfokus kepada hasil yang dicapai peserta didik, namun bagaimana proses 
pembelajaran yang efektif mampu memberikan pemahaman yang baik, kecerdasan, ketekunan, kesempatan dan mutu serta dapat memberikan perubahan prilaku dan mengaplikasikannya. Untuk itu setiap satuan pendidikan melakukan perencanaan pembelajaran, pelaksanaan proses pembelajaran serta penilaian proses pembelajaran untuk meningkatkan efisiensi dan efektivitas ketercapaian kompetensi lulusan.

Andriani (2014) dalam penelitiannya menyatakan bahwa belum optimalnya pengembangan kurikulum (program) berakibat seolah-olah kurikulum adalah sebuah dokumen yang tidak mempunyai fungsi penting dalam pendidikan sehingga akan berakibat juga pada kualitas out put siswa. Kelemahan sistem pendidikan di Indonesia adalah banyaknya beban kurikulum yang diterapkan di SMK.

Afifah (2011) menyatakan komunikasi adalah kemampuan mengirimkan pesan dengan jelas, manusiawi, efisien dan menerima pesan secara akurat. Komunikasi adalah suatu proses penyampaian informasi (pesan, ide, gagasan) dari satu pihak kepada pihak lain agar terjadi saling mempengaruhi diantara keduanya. Komunikasipada hakikatnya merupakan proses penyampaian pesan dari pengirim kepada penerima. Hubungan komunikasi dan interaksi antara si pengirim dan si penerima, dibangun berdasarkan penyusunan kode atau simbol bahasa oleh pengirim dan pembongkaran ide tau simbol bahasa oleh penerima.

Halimah (2017) menyatakan soft skills adalah keterampilan seseorang dalam dalam berinteraksi dengan orang lain (interpersonal skills) dan keterampilan dalam mengatur dirinya sendiri (intrapersonal) yang mampu mengembangkan unjuk kerja secara maksimal. Seseorang yang mampu berinteraksi dengan orang lain dalam keseharian pastinya memiliki soft sklls dalam berkomunikasi.

Sumarmo (2010) menyatakan soft skills adalah kekuatan yang mampu menggerakkan seseorang untuk berbuat yang terbaik, bekerja dengan penuh kesungguhan, bekerja memenuhi kaidahkaidah perilaku profesional. Dalam lingkup pembelajaran maka penguasaan soft skills akan mengiringi penguasaan hard skills, dengan kata lain dengan penguasaan hard skills akan baik jika didukung oleh kekuatan soft skills yang baik pula.

Efendi (2010) menyatakan soft skills diartikan sebagai perilaku interpersonal dan intrapersonal yang mampu mengembangkan dan memaksimalkan kinerja yang humanis. Menurut Bancino (2007), soft skills adalah suatu istilah sosiologis yang menunjuk pada sekelompok sifat kepribadian, keselarasan sosial, kemampuan berbahasa, kebiasaan personal, keramahtamahan, dan optimisme seseorang yang menempatkan orang pada berbagai tingkatan. Soft skills melengkapi hard skills, yang diperlukan secara teknis dalam kehidupan. Soft skills adalah sifat personal yang penting untuk meningkatkan interaksi individual, prestasi kerja, dan prospek karir.

Rogers (1981) mengemukakan bahwa komunikasi adalah suatu proses dimana dua orang atau lebih membentuk atau melakukan pertukaran informasi dengan satu sama lainnya yang pada gilirannya akan tiba pada saling pengertian yang mendalam. hakikat suatu ubungan dengan adanya suatu pertukaran informasi (pesan), dimana ia menginginkan adanya perubahan sikap dan tingkah 
laku serta kebersamaan dalam menciptakan saling pengertian dari orang-orang yang ikut serta dalam suatu proses komunikasi.

Mulyana (2008: 18) menyampaikan komunikasi merupakan proses yang me-mungkinkan seseorang (komunikator) menyampaikan rangsangan (biasanya lambang-lambang verbal) untuk mengubah perilaku orang lain (komunikate). Komunikasi yang dimaksud pada hal ini yaitu mengenai bagaimana cara membagi pada orang lain apa yang ada dalam pemikiran kita.

Moekijat (2003: 3) menyatakan komunikasi adalah seni mengembangkan dan mendapatkan pengertian diantara orang- orang. Komunikasi adalah proses penukaran informasi dan perasaan diantara dua orang atau lebih, dan penting bagi manajemen yang efektif. Daryanto (2010) mengemukakan komunikasi ialah sebuah proses pemberian informasi dari seseorang ke orang lain melalui berbagai cara agar informasi yag diberikan dapat diterima. Cangara (2004:18) menyatakan komunikasi adalah suatu proses dimana dua orang atau lebih membentuk atau melakukan pertukaran informasi dengan satu sama lainnya, yang pada gilirannya akan tiba pada saling pengertian yang mendalam .

Pembelajaran berbasis soft skills sangatlah penting untuk diberikan kepada siswa sebagai bekal mereka terjun ke dunia kerja dan industri, khususnya bagi sekolah kejuruan yang mencetak lulusannya siap pakai di dunia kerja karena tuntutan dunia kerja lebih menekankan pada kemampuan soft skills. Soft skills dalam pendidikan diajarkan pada semua mata pelajaran. Beberapa soft skills dapat dikembangkan dalam mata pelajaran Matematika.

Pembelajaran soft skills komunikasi dilakukan dengan mengidentifikasi karakteristik siswa dan mengidentifikasi tujuan pembelajaran. Karakteristik siswa digunakan untuk mengelola pembelajaran yang baik digunakan. Karakteristik siswa diambil dengan menggunakan angket kemampuan diri. Tujuan pembelajaran digunakan untuk mengarahkan pembelajaran sesuai dengan perangkat pembelajaran.

Menurut Herman (2006: 4) Ada 3 hal yang tak dapat dipisahkan manakala pendidik menerapkan manajemen performen, target belajar, coaching dan feedback serta reinforcement. Target belajar menjelaskan pilihan skills ataupun soft skills akan dilatihkan atau sebagai content. Coach adalah pendidik yang berfungsi untuk memberi motivasi, membantu mengembangkan skills dan memberi penguatan dan balikan. Ada tiga peran seorang coach: pertama berdasarkan hasil penilaian memberi feedback secara perorangan. Kedua adalah membantu siswa untuk dapat membelajarkan dirinya sendiri melalui proses interaksi dengan ahli yang mampu mendorong memahami potensi diri dan pengembangan diri. Ketiga adalah melayani siswa dengan pemberian pengalaman belajar.

Pembelajaran soft skills komunikasi dilakukan dengan mengidentifikasi karakteristik siswa dan mengidentifikasi tujuan pembelajaran. Karakteristik siswa digunakan untuk mengelola pembelajaran yang baik digunakan. Karakteristik siswa diambil dengan menggunakan angket kemampuan diri. Tujuan pembelajaran digunakan untuk mengarahkan pembelajaran sesuai dengan perangkat pembelajaran. 
Sumarmo (2012) menyatakan Komunikasi matematis merupakan modal dasar dalam menyelesaikan, mengeksplorasi, dan menginvestigasi matematika dan merupakan wadah dalam beraktivitas sosial dengan temannya, berbagi pikiran dan penemuan, curah pendapat, menilai dan mempertajam ide untuk meyakinkan orang lain. Adanya komunikasi matematis, siswa dapat mengembangkan diri dengan baik baik pikiran, dan keyakinan diri. Pentingnya komunikasi matematis dalam pembelajaran matematika dikemukakan Darta (2004) diantaranya adalah : (a) melalui komunikasi ide matematika dapat digali dalam berbagai prespektif; (b) mempertajam cara berpikir untuk meningkatkan kemampuan melihat keterkaitan antara konten matematika; (c) untuk mengukur pemahaman matematis; (d) mengkonstruksikan pengetahuan matematika, mengembangkan pemecahan masalah, meningkatkan penalaran, menumbuhkan rasa percaya diri, serta meningkatkan ketrampilan sosial; dan (e) menumbuhkembangkan kemampuan berpikir siswa.

Yulianto (2018) mengemukakan Komunikasi matematis merupakan hal penting yang harus dikuasai dalam pembelajaran matematika. Matematika selain sebagai pemecahan masalah, penemuan pola, dan menarik kesimpulan namun juga sebagai alat untuk mengkomunikasikan ide pemikiran dengan jelas dan ringkas. Pembelajaran matematika dalam kelas juga termasuk ke dalam pembelajaran sosial karena melibatkan minimal dua pihak yaitu guru dan siswa.

Jazuli (2015:215) menyatakan komunikasi matematis adalah kemampuan siswa dalam hal menjelaskan suatu algoritma dan cara unik untuk pemecahan masalah, kemampuan siswa mengkonstruksi dan menjelaskan sajian fenomena dunia nyata secara grafis, kata-kata atau kalimat, persamaan, tabel dan sajian secara fisik atau kemampuan siswa memberikan dugaan tentang gambargambar geometri.Komunikasi secara konseptual yaitu memberitahukan dan menyebarkan berita, pengetahuan, pikiran-pikiran dan nilai-nilai dengan maksud untuk menggugah partisipasi agar hal-hal yang diberitahukan menjadi milik bersama.

Berdasarkan pendapat-pendapat di atas dapat ditarik kesimpulan bahwa komunikasi matematis merupakan proses penyampaian informasi matematika dari seseorang kepada orang lain melalui lisan atau tulis yang bertujuan memperjelas masalah yang diberikan serta mengkonstruksi dan menjelaskan sajian fenomena dunia nyata secara grafis, kata-kata atau kalimat, persamaan, tabel dan sajian secara fisik atau kemampuan siswa memberikan dugaan tentang gambar-gambar geometri.

\section{METODE}

Metode yang digunakan dalam penelitian ini adalah metode eksperimen dengan pengambilan sampel secara acak. Dalam penelitian ini diperlukan dua kelompok, pertama adalah kelompok eksperimen yang diberi perlakuan berupa pembelajaran menggunakan pembelajaran soft skill komunikasi dan yang kedua kelompok kontrol, yang diberi pembelajaran biasa yaitu pembelajaran yang sehari-hari dilakukan di sekolah. Sebelum dan sesudah perlakuan kedua kelompok diberi tes. Berdasarkan uraian di atas maka desain penelitian menggunakan Nonequivalent Control Group Design sebagai berikut : 


$\begin{array}{llll}\mathrm{A}_{1}: & \mathrm{O} & \mathrm{X} & \mathrm{O} \\ \mathrm{A}_{2}: & \mathrm{O} & & \mathrm{O}\end{array}$

(Emzir: 2017)

Keterangan :

A $\quad=$ Pengambilan sampel secara acak kelas

$\mathrm{O}=$ Tes awal dan tes akhir

$\mathrm{X} \quad=$ Pemberian perlakuan berupa pembelajaran soft skill komunikasi.

Penelitian ini dilakukan di kelas XI siswa SMK Negeri Unggul Terpadu Lampung Tengah, sedangkan sampelnya dipilih 2 kelas XI di SMK Negeri Unggul Terpadu. Instrumen yang digunakan pada penelitian ini adalah perangkat tes berbentuk soal uraian, satu set soal untuk mengukur kemampuan komunikasi matematis.

Prosedur penelitian terdiri dari dari 1) Tahap Persiapan, 2) Tahap Pelaksanaan dan 3) Tahap Evaluasi. Pada tahap persiapan, sebelum penelitian ini dilaksanakan terlebih dahulu diadakan persiapan-persiapan yang dipandang perlu, antara lain : melakukan studi pustaka mengenai kemampuan komunikasi matematis dan pembelajaran soft skill komunikasi, membuat rancangan pembelajaran untuk kemampuan komunikasi matematis dengan menggunakan pembelajaran soft skill komunikasi, maupun menggunakan pendekatan kontekstual. Setelah persiapan dianggap cukup, dilanjutkan pemilihan sampel dan dilanjutkan dengan penyusunan instrumen penelitian, melakukan uji coba coba instrumen serta merevisi instrumen tersebut agar dapat digunakan dalam penelitian.

Persiapan-persiapan yang dipandang perlu, antara lain : melakukan studi kepustakaan mengenai kemampuan komunikasi matematis dan pembelajaran soft skill komunikasi, membuat rancangan pembelajaran kemampuan komunikasi matematis dengan menggunakan pembelajaran soft skill komunikasi, maupun menggunakan pendetatan biasa. Setelah persiapan dianggap cukup, dilanjutkan pemilihan sampel dan dilanjutkan dengan penyusunan instrumen penelitian, melakukan uji coba coba instrumen serta merevisi instrumen tersebut agar dapat digunakan dalam penelitian. Dalam penelitian ini penulis berperan sebagai guru pengajar yang memberikan materi dan sekaligus tugas kepada siswa, dengan pertimbangan untuk mengurangi bias karena perbedaan perlakuan pada masingmasing kelas. Pelaksanaan pembelajaran didua kelas dilaksanakan sesuai dengan jadwal yang ada di SMK yaitu 4 jam pelajaran (4 x 45 menit) untuk setiap minggu. Sebagai langkah terakhir, yaitu pemberian tes akhir kepada kedua kelompok, kemudian dihitung N-gain peningkatannya. 
Pembelajaran Soft Skill Komunikasi Untuk Meningkatkan Kemampuan Komunikasi Matematis Siswa, Muhammad Nur Wahyu, Sugeng Sutiarso dan Haninda Bharata

Berikut ini ditampilkan beberapa contoh tes kemampuan komunikasi matematik matematis yang digunakan dalam studi ini terdapat

\section{HASIL}

Dari hasil perhitungan data dengan menggunkan SPSS 20 didapat hasil penelitian sebagai berikut

\section{Tabel 1.}

Kemampuan Komunikasi Matematis.

\begin{tabular}{ccccccccc}
\hline \multirow{2}{*}{ Variabel } & \multirow{2}{*}{ Statistik } & \multicolumn{2}{c}{$\begin{array}{c}\text { Pembelajaran Soft Skill } \\
\text { komunikasi }\end{array}$} & \multicolumn{2}{c}{ Pembelajaran Konvensional } & \multirow{2}{*}{ SMI } \\
& & Pre tes & Pos tes & N-Gain & Pre tes & Pos tes & N-Gain & \\
\hline Kemampuan & Rata-rata & 63,24 & 72,72 & & 61,28 & 69,84 & & 75 \\
Komunikasi & $\%$ SMI & 0,8432 & 0,9696 & 0,806 & 0,8171 & 0,9312 & 0,624 & \\
Matematis & $\mathrm{N}$ & 25 & 25 & & 25 & 25 & & \\
\hline
\end{tabular}

Setelah dilakukan pengujian normalitas terhadap pretes, postes dan $\mathrm{N}$-gain dengan menggunakan uji Kolmogorov Smirnov ternyata sebaran data untuk kemampuan komunikasi matematis berdistribusi normal. Untuk menguji kemampuan komunikasi matematis maka digunakan uji Independent t-test. Hipotesis yang akan diuji untuk hasil pos tes kemampuan komunikasi matematis adalah sebagai berikut :

$\mathrm{H}_{0}$ : Tidak terdapat perbedaan peningkatan kemampuan komunikasi matematis siswa antara pembelajaran soft skill komunikasi dan pendekatan biasa

$\mathrm{H}_{1}$ : Peningkatan kemampuan komunikasi matematis siswa pada yang pembelajarannya menggunakan pembelajaran soft skill komunikasi lebih baik daripada pembelajaran biasa.

Adapun hipotesis untuk menguji $\mathrm{N}$-gain diformulasikan sebagai berikut :

$\mathrm{H}_{0}$ : Tidak terdapat perbedaan peningkatan kemampuan komunikasi matematis siswa SMK antara yang pembelajarannya menggunakan pembelajaran soft skill komunikasi maupun pembelajaran biasa $\mathrm{H}_{1}$ : Peningkatan kemampuan komunikasi matematis siswa lebih baik dari pada yang pembelajarannya menggunakan pembelajaran soft skill komunikasi lebih baik daripada pembelajaran biasa.

Adapun hasil pengujian dengan Independent Sample t-Test, kami tampilkan pada tabel berikut ini :

\section{Tabel 2}

Uji Postes dan N-gain Kemampuan komunikasi Matematis

\begin{tabular}{llccc}
\hline Perhitungan & \multicolumn{1}{c}{ Kelas } & N & Sign. & $\mathbf{H}_{\mathbf{0}}$ \\
\hline Postes & Eksperimen & 25 & 0,01 & $\mathrm{H}_{\mathrm{o}}$ ditolak \\
& Kontrol & 25 & & \\
\hline N-gain & Eksperimen & 25 & 0,01 & $\mathrm{H}_{\mathrm{o}}$ ditolak \\
& Kontrol & 25 & & \\
\hline
\end{tabular}


Berdasarkan Tabel 2, didapat temuan sebagai berikut: pencapaian dan peningkatan kemampuan siswa dalam kemampuan komunikasi matematis yang belajarnya lebih baik dibandingkan konvensional. Pencapaian dan peningkatan untuk kedua kelas baik komunikasi maupun konvensional berada pada kategori sedang (untuk kelas komunikasi 68\% dari SMI, sedangkan konvensional 59,65\% dari SMI).

Adapun alasan penerapan pembelajaran soft skill komunikasi dapat meningkatkan kemampuan komunikasi matematis, karena menurut definisi pembelajaran Soft skill komunikasi adalah pendekatan yang mengaitkan konsep-konsep pembelajaran dengan mengkaitkan penyelesaian berbasis komunikasi matematis menyebabkan siswa dapat lebih memahami konsep matematis dari permasalahan matematis siswa, Hal ini menyebabkan pengajaran matematika yang lebih menarik.

Hasil dan pembahasan berisi hasil analisis fenomena di wilayah penelitian yang relevan dengan tema kajian. Hasil penelitian hendaknya dibandingkan dengan teori dan temuan penelitian yang relevan

\section{KESIMPULAN}

Penelitian ini memberikan kesimpulan sebagai berikut: Pencapaian dan peningkatan kemampuan siswa dalam komunikasi matematis siswa yang pembelajarannya menggunakan pendekatan kontekstual lebih baik dibandingkan pembelajaran konvensional. Kemampuan pemahaman matematis baik pada pada kelas kontekstual maupun konvensional berada pada kategori sedang, namun pada kemampuan komunikasi kedua kelas berada pada kategori kurang. Berdasarkan kesimpulan yang telah diutarakan maka saran dalam penelitian ini adalah pembelajaran Kontekstual dapat digunakan sebagai alternatif yang dapat diplih untuk model pembelajaran dalam matematika terutama untuk topik-topik terpilih dalam matematika.

\section{DAFTAR PUSTAKA}

Afifah, Nurul. 2011. Meningkatkan Kemampuan Komunikasi Siswa SMP Melalui Penerapan Pendekatan Creatif Problem Solving (CPS) Terhadap Siswa Kelas VII SMPN 14. Bandung: Skripsi FMIPA Pendidikan Matematika UPI

Andriani, Meiri. 2014. Penerapan model pembelajaran Guided Inquiry dalam Meningkatkan Aktivitas dan Prestasi Belajar Fisika pada Materi Suhu dan Kalor Siswa Kelas Xc SMA XAVERIUS 2 Jambi.Jambi: FKIP Universitas Jambi

Bancino, Randy \& Claire Zevalkink. 2007. "Soft skills: The New Curiculum for Hard-core Technical Professionals". diakses tgl 17 mei 2019

Cangara, Hafied. 2004. “Pengantar Ilmu Komunikasi”. Jakarta: PT. Rajagrafindo.

Darta. 2004. Pembelajran Matematika Kontekstual dalam Upaya Mengembangkan Kemampuan Pemecahan Masalah dan Komunikasi Matematika Mahasiswa Calon Guru. Bandung. Tesis FMIPA Pendidikan Matematika UPI

Daryanto. 2010. Media Pembelajaran. Yogyakarta: Gava Media 
Pembelajaran Soft Skill Komunikasi Untuk Meningkatkan Kemampuan Komunikasi Matematis Siswa, Muhammad Nur

Efendi, R. 2010. "Kemampuan Fisika siswa indonesia dalam TIMMS (Trend of Internasional on Mathematics and Science study)". http:/www.fi.itb.ac.id (diunduh 4 mei 2019).

Emzir. 2017. “Metodologi penelitian pendidikan Kualitatif dan Kuantitatif”.Jakarta. PT. RajaGrafindo Persada.

Halimah, Leli (2017). Ketrampilan Mengajar sebagai Inspirasi untuk Menjadi Guru yang Excellent di Abad Ke-21. Bandung: PT. Rafika Aditama.

Jazuli, Akhmad. 2015. "Berfikir Kreatif dalam Kemampuan Komunikasi Matematika” dalam http://eprints.uny.ac.id/7025/1/P11-Akhmad\%20Jazuli.pdf. diakses 30 Januari 2018.

Moekijat. 2003. Managemen Sumber Daya Manusia. Bandung: Pionir Jaya.

Mulyana, Deddy. 2008. Ilmu Komunikasi Sebuah Pengantar.Bandung: Remaja Rosdakarya.

Rogers \& D. Lawrence Kincaid.1981. Communication network: Toward a new paradigm for research. New York: Free Press.

Sumarmo, Utari. 2010. Berpikir dan Disposisi Matematik : Apa, Mengapa, dan Bagaimana Dikembangkan pada Peserta Didik. Disampaikan pada Seminar Nasional di Jurusan Pendidikan Matematika FPMIPA UNY

Sumarmo, Utari, 2012. Pendidikan Karakter serta Pengembangan Berpikir dan Disposisi Matematik dalam pembelajaran Matematika. Nasional Seminar of Mathematics Education at Widya Mandira Katholic University Kupang NTT, April 2012. Makalah dimuat dalam Suryadi, D, Turmudi, Nurlaelah, E. (Editor). Kumpulan Makalah Proses Berpikir dan Disposisi Matematik dan Pembelajarannya. 2014. Jurusan Pendidikan Matematika FPMIPA UPI.

Yulianto, 2018. Desain Soft Skills Pembelajaran Matematika Berbasis Model Generatif Untuk Meningkatkan Kemampuan Komunikasi Matematis Siswa. Lampung : Tesis 